\title{
Dual-linker gold nanoparticles as adjuvanting carriers for multivalent display of recombinant influenza hemagglutinin trimers and flagellin improve the immunological responses in vivo and in vitro
}

This article was published in the following Dove Press journal:

International Journal of Nanomedicine

4 July 2017

Number of times this article has been viewed

\author{
Chao Wang \\ Wandi Zhu \\ Bao-Zhong Wang \\ Center for Inflammation, \\ Immunity and Infection, Georgia State \\ University Institute for Biomedical \\ Sciences, Atlanta, GA, USA
}

\begin{abstract}
Vaccination is the most cost-effective means of infectious disease control. Although current influenza vaccines are effective in battling closely matched strains, such vaccines have major limitations such as the requirement to produce new vaccines every season, an eggdependent production system, long production periods, uncertainty in matching the vaccine to circulating strains, and the inability to react to new influenza pandemics resulting from genetic drift or shift. To overcome the intrinsic limitations of the conventional influenza vaccine, we have designed dual-linker gold nanoparticles (AuNPs) conjugated with both recombinant trimetric A/Aichi/2/68 (H3N2), hemagglutinin (HA) and TLR5 agonist flagellin (FliC) as a novel vaccine approach. Click chemistry and metal-chelating reactions were used to couple the two proteins. The conjugated proteins were found to possess high coupling specificity, high stability in harsh environments, high conjugation efficiency, and the ability to keep the appropriate protein conformations for immunogenicity and immunostimulation. Both AuNPs-HA/ FliC and AuNPs-HA formulations induced higher levels of antibody responses than a mixture of soluble HA and FliC proteins when administered via a single intranasal immunization in mice. To further investigate the adjuvancy of these nanoparticles, in vitro experiments were conducted in both the JAWS II dendritic cell (DC) line and bone marrow-derived DC (BMDC) models. The results showed that dual-conjugated AuNPs were rapidly targeted and taken up by DCs. Consequently, DCs were induced toward maturation, as demonstrated by high levels of cytokine secretions and membrane costimulatory molecule expression. T cell proliferation was observed when splenic T cells were cocultured with AuNPs-HA/FliC-primed BMDCs. These results suggest that dual-conjugated AuNPs are effective at simultaneously displaying antigens and adjuvants in an oriented, multivalent format and can promote a strong immune response by activating DCs and T cells.
\end{abstract}

Keywords: adjuvant, co-delivery, dendritic cells, influenza vaccine, gold nanoparticle

\section{Introduction}

Influenza is a contagious respiratory pathogen that can cause epidemics and pandemics due to its rapid transmission and frequent genetic alteration. Influenza A virus expresses two dominant membrane proteins, hemagglutinin (HA) and neuraminidase (NA). Current commercial inactivated split or live attenuated influenza vaccines provide protective immunity by triggering the immune system to produce neutralizing antibodies 
(Abs) against HA and NA. ${ }^{1}$ However, rapid mutations in HA and NA can reduce or eliminate the effectiveness of previous vaccinations. ${ }^{2}$ Once a new virus strain emerges, the slow manufacturing process based on embryonated hen eggs limits the possible supply of new vaccines. Furthermore, the live attenuated virus vaccines possess safety issues, such as the risk of reactogenicity and unfavorable side effects. ${ }^{3}$ Therefore, the development of a new influenza vaccine approach which can support rapid vaccine production and provide broader protection against possible genetic drifts and shifts is highly desirable.

Nanoscale materials have provided unprecedented opportunities in building novel vaccine delivery systems because of how they can be designed to mimic natural pathogens and stimulate immune processes. ${ }^{4-8}$ By various self-assembling reactions, antigens can be deposited onto the surfaces of nanoparticles at high density. ${ }^{9}$ The repetitive antigen structures can act as multivalent ligands and can cross-link antigen receptors on immune cell surfaces for better targeting and long-term stimulation. ${ }^{10}$ Among these nanomaterials, gold nanoparticles (AuNPs) are appearing increasingly attractive as an integral platform for both antigens and adjuvants because of their advantages, such as nontoxicity, biocompatibility ease of fabrication, and various surface modifications. ${ }^{11}$ Moreover, the bio-inert properties of AuNPs prevent the production of anti-AuNPs Abs and side effects.

Besides the use of new nanoscale materials, the inclusion of adjuvants is necessary to improve the immunogenicity of vaccines. These adjuvants can trigger the host innate signaling pathways to facilitate the maturation of antigenpresenting cells (APCs), resulting in a more robust immune response. The bacterial flagella protein, flagellin (FliC), is a potent adjuvant candidate which can be recognized by TLR5expressed APCs in skin and mucosa. ${ }^{12}$ Recent studies have demonstrated that FliC-conjugated nanoparticles are capable of specifically increasing TLR5 stimulation and inducing more pronounced innate immunostimulation compared to soluble FliC..$^{13}$

We hypothesize that using AuNPs as a multifunctionalized vaccine carrier to co-deliver both antigen and adjuvant to APCs can trigger more effective immune responses versus other carriers. We formulated dual-linker AuNPs by conjugating both recombinant trimeric HA from influenza A/Aichi/2/68 (H3N2) ${ }^{14}$ and FliC (adjuvant) on the same nanoparticle in a stably anchored, favorably oriented, multivalent presentation format. By using this design, we aim to enhance the antigen/adjuvant uptake by dendritic cells (DCs) to drive DC maturation, antigen processing, and antigen presentation.
In the immunization study, a single-dose intranasal (IN) immunization was given to mice. The results of this study showed that the levels of antigen-specific Abs were significantly increased by using the dual-conjugated AuNP formulation versus other formulations. In in vitro studies, the AuNPs-HA/FliC vaccines were capable of rapidly delivering antigens and adjuvants to the same compartment within APCs and triggering the TLR5 signaling pathways, characterized by the upregulation of related cytokine and costimulatory molecule expression. Consequently, antigenic epitopes were effectively processed and cross-presented by APCs for further induction of $\mathrm{T}$ cell-mediated immunity.

\section{Materials and methods Materials}

Azido polyethylene glycol (PEG) thiol ( $\mathrm{N}_{3}$-PEG-SH) was purchased from Nanocs (NY, USA). Gold(III) chloride trihydrate

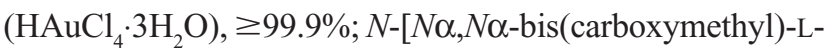
lysine]-12-mercaptododecanamide (SH-NTA), $\geq 90.0 \%$; dimethyl sulfoxide (DMSO), $\geq 99.9 \%$; copper (II) sulfate pentahydrate, $\geq 98.0 \%$; 4-aminophenyl propargyl ether, $95.0 \%$; tetrahydrofuran (THF), $\geq 99.9 \%$; $N$-(3dimethylaminopropyl)- $N^{\prime}$-ethylcarbodiimide hydrochloride (EDC), $\geq 99.0 \%$; and 11-mercapto-1-undecanol, 99.0\%, were purchased from Sigma-Aldrich Co. (St Louis, MO, USA). E-pure water $(18.2 \mathrm{M} \Omega \cdot \mathrm{cm})$ was used for all regents' preparation. Recombinant trimeric HA from A/Aichi/2/68 (Aichi, H3N2) and FliC from Salmonella were purified as previously described. ${ }^{14,15}$ The full-length flagellin gene from Salmonella typhimurium was a gift from Dr Alan Aderem. The HA gene from A/Aichi/2/68 was obtained from David Steinhauer.

\section{Generation of $18 \mathrm{~nm}$ AuNPs}

AuNPs were prepared as previous described. ${ }^{16}$ Briefly, $36 \mathrm{~mL}$ of $1 \mathrm{mM}$ chloroauric acid was kept well mixed under boiling conditions for $10 \mathrm{~min}$. Then, $4 \mathrm{~mL}$ of $90 \mathrm{mM}$ sodium citrate was quickly added to the solution. The solution was stirred for $20 \mathrm{~min}$ to allow full reduction. The reddish color solution was cooled down to room temperature. The solution was stored away from light at $4^{\circ} \mathrm{C}$. The size of AuNPs was confirmed by using a transmission electron microscope (TEM) and dynamic light scattering (DLS; Malvern Nano-ZS; Malvern Instruments, Malvern, UK). Ultraviolet (UV)-visible absorbance spectra were recorded at room temperature.

\section{Preparation of Alkyne-FliC}

Alkyne-FliC was prepared according to a modified EDC method. ${ }^{17}$ Briefly, $1 \mathrm{~mL}$ of $2.4 \mathrm{mg} / \mathrm{mL}$ FliC (PBS, $\mathrm{pH}=7.4$ ), $12 \mu \mathrm{L}$ of 4-aminophenyl propargyl ether (100 mM in THF), 
and $11 \mu \mathrm{L}$ of EDC (100 $\mathrm{mM}$ in PBS) were mixed in $10 \% \mathrm{v} / \mathrm{v}$ THF/PBS overnight at $4^{\circ} \mathrm{C}$. The crude alkyne-FliC was purified by a Microcon centrifugal filter unit (molecular weight cutoff [MWCO] $10 \mathrm{kDa}$ ) and washed with PBS. Purified alkyne-FliC was stored under $4^{\circ} \mathrm{C}$. The molar concentration of alkyne-FliC was determined by Bradford protein assay. ${ }^{18}$

\section{Preparation of dual-linker modified AuNPs}

Briefly, $1 \mathrm{~mL}(0.005 \mathrm{nmol})$ AuNPs solution was mixed with $10 \mu \mathrm{L}$ of $10 \mathrm{mM}$ Tween 20 for $30 \mathrm{~min}$ to stabilize the particles. After adding $10 \mu \mathrm{L}$ of $1 \mathrm{mg} / \mathrm{mL}$ SH-NTA in DMSO, the solution was continually kept mixing for $2 \mathrm{~h}$. Then, $100 \mu \mathrm{L}$ of $100 \mu \mathrm{M}$ azide-PEG-SH solution was added. Two more hours mixing was required to allow for the complete exchange of citrate with thiol. The mixture was purified by centrifugation $\left(-32,869 \times{ }^{\prime} g\right.$ for $30 \mathrm{~min}$ at $\left.4^{\circ} \mathrm{C}\right)$ twice. The supernatant was removed, and the pellet was re-suspended in $1 \mathrm{~mL} 18.2 \mathrm{M} \Omega \cdot \mathrm{cm}$ E-pure water.

\section{Preparation of AuNPs-HA/FliC conjugates via metal-chelating and click chemistry reactions}

Briefly, $33 \mu \mathrm{L}$ of $30 \mathrm{mM}$ copper (II) sulfate pentahydrate and $17 \mu \mathrm{L}$ of alkyne-FliC $(1.5 \mathrm{mg} / \mathrm{mL})$ were added to $1 \mathrm{~mL} \mathrm{SH}-$ NTA and azide-PEG-SH AuNPs and kept mixing for $30 \mathrm{~min}$. After adding $140 \mu \mathrm{L} \mathrm{HA}(1.8 \mathrm{mg} / \mathrm{mL})$, the solution was mixed overnight to allow complete protein conjugation at $4^{\circ} \mathrm{C}$. The mixture was purified by centrifugation $\left(30,563 \times^{\prime} g\right.$ for $20 \mathrm{~min}$ at $4{ }^{\circ} \mathrm{C}$ ) twice. The pellet was redispersed in $1 \mathrm{~mL}$ PBS. The particles size was characterized by TEM and DLS.

\section{Quantification and stability of HA/FliC- conjugated AuNPs}

Conjugated proteins were released from AuNPs by displacing the linker from particles using $0.1 \mathrm{mM} 11$-mercapto-1undecanol and heating. Samples were separated through sodium dodecyl sulfate polyacrylamide gel electrophoresis (SDS-PAGE) gel and stained with Coomassie blue. Band densitometry, calibrated with an HA protein standard (Figure S1), was used to determine the mass of protein released from AuNPs. The concentration was also confirmed by a Bradford protein assay.

\section{TLR5-specific bioactivity assay}

A HEK 293T (human embryonic kidney 293T, CRL-3216; American Type Culture Collection [ATCC], Manassas, VA, USA) cell-based assay with modifications was used to determine the bioactivity of conjugated FliC on AuNPs. ${ }^{19}$ HEK 293T cells were grown in Dulbecco's Modified Eagle's Medium (DMEM; Thermo Fisher Scientific, Waltham, MA, USA) containing 10\% fetal bovine serum (FBS; heat inactivated) (Thermo Fisher Scientific), $2 \mathrm{mM} \mathrm{L}$-glutamine (Thermo Fisher Scientific), and 1\% penicillin/streptomycin. In brief, $90 \%$ confluent $293 \mathrm{~T}$ cells in a $75 \mathrm{~cm}^{2}$ flask were transfected with $10 \mu \mathrm{g}$ of plasmid pUNO1-hTLR5 (InvivoGen, San Diego, CA, USA) and reporter plasmid pGL4.3 (Promega Corporation, Fitchburg, WI, USA) by using Lipofectamine ${ }^{\circledR} 2000$ (Thermo Fisher Scientific) following the manufacturer's instructions. The ratio between pTLR5 and pGL4.3 ranged from 5:1 to 10:1. After $24 \mathrm{~h}$ of transfection, cells were split into a $96-$ well plate with $5 \times 10^{4}$ cells/well. Soluble FliC and AuNPs-HA/FliC were serially diluted from $2 \mu \mathrm{g} / \mathrm{mL}$ to $1.6 \mathrm{ng} / \mathrm{mL}$, were prepared with $1 \%$ FBS culture medium, and used to treat cells for stimulation. After $5 \mathrm{~h}$ incubation, $100 \mu \mathrm{L}$ of Luciferase Assay Reagent (Promega Corporation) was added to each well. Luciferase activity was read with GloMax ${ }^{\circledR}$-Multi Detection System (Promega Corporation).

\section{Hemagglutination assay}

Hemagglutination tests were performed based on the World Health Organization (WHO) protocol with modifications. ${ }^{20}$ Briefly, soluble HA and AuNPs-HA/FliC $(40 \mu \mathrm{g} / \mathrm{mL})$ were serially twofold diluted in a round-bottomed $96-$ well plate. An equal volume of turkey blood cells $(0.5 \%)$ was added into each well, and all samples were incubated at $25^{\circ} \mathrm{C}$ for $30 \mathrm{~min}$ to develop. HA titers were recorded.

\section{DCs preparation}

JAWS II cells (CRL-11904; American Type Culture Collection [ATCC]) were grown in a $37^{\circ} \mathrm{C}$ and $5 \% \mathrm{CO}_{2}$ incubator using alpha minimum essential medium with ribonucleosides, deoxyribonucleosides, $4 \mathrm{mM}$ L-glutamine, $1 \mathrm{mM}$ sodium pyruvate, $5 \mathrm{ng} / \mathrm{mL}$ recombinant murine granulocyte macrophage colony-stimulating factor (GM-CSF; R\&D Systems, Inc., Minneapolis, MN, USA), and 20\% FBS. Cells were seeded at $10^{6}$ cells/well in six-well cell culture plate and treated with different stimulators.

Female BALB/c mice (age: 6-8 weeks) were obtained from Envigo/Harlan (Huntingdon, UK). Bone-marrow-derived DCs were obtained from femoral and tibial bones. Briefly, BM cells were plated at $2 \times 10^{5}$ cells $/ \mathrm{mL}$ in $24-w e l l$ cell culture plates with RPMI-1640 supplemented with 10\% FBS, $10 \mathrm{ng} / \mathrm{mL}$ recombinant murine GM-CSF, $400 \mathrm{mM}$ L-glutamine, and $100 \mathrm{U}$ of penicillin/streptomycin for 6 days. The culture medium was exchanged for fresh medium every 2 days. 


\section{Ethics statement}

This study was carried out in strict accordance with the recommendations found in the Guide of the Care and Use of Laboratory Animals of the National Institutes of Health (NIH). All animal studies were conducted with the approval of the Institutional Animal Care and Use Committee of Georgia State University and were in full compliance with the committee's guidelines.

\section{Immunizations and analysis of $A b$ responses}

Groups of five 6 to 8 -week-old female BALB/c mice (Envigo/Harlan) were IN immunized once with $5 \mu \mathrm{g} / \mathrm{mL}$ HA and $0.25 \mu \mathrm{g} / \mathrm{mL}$ FliC of AuNPs-HA/FliC, AuNPs-HA, soluble $\mathrm{HA} / \mathrm{FliC}$, or PBS. Sera were collected at 21 days after immunization. The antigen-specific IgG levels of the individual mouse sera were determined by ELISA. ${ }^{14}$ Briefly, 96-well microtiter plates (Nunc; Thermo Fisher Scientific) were coated with $100 \mu \mathrm{L} /$ well of inactivated Aichi virus $(4 \mu \mathrm{g} / \mathrm{mL})$ in coating buffer. Following blocking with $200 \mu \mathrm{L}$ of $1.5 \%$ bovine serum albumin (BSA), serum samples were serially twofold diluted in a volume of $100 \mu \mathrm{L}$ and added into wells. After $2 \mathrm{~h}$ incubation, plates were washed and incubated with horseradish peroxidase-labeled goat anti-mouse IgG at $37^{\circ} \mathrm{C}$ for $1 \mathrm{~h}$. Tetramethylbenzidine (TMB) substrates (Thermo Fisher Scientific) were used to develop color. Absorption was read at $450 \mathrm{~nm}\left(\mathrm{OD}_{450}\right)$ using an ELISA reader (model 680; BioRad Laboratories Inc., Hercules, CA, USA).

\section{Confocal laser scanning micrograph}

Fluorescence imaging samples were prepared as previously described..$^{21}$ Briefly, JAWS II cells were seeded on a small coverslip in six-well plates and treated with Alexa Fluor 488 (Thermo Fisher Scientific)-conjugated AuNPs-HA/FliC (the final concentration of $\mathrm{HA}$ and FliC was $5 \mu \mathrm{g} / \mathrm{mL}$ and $0.5 \mu \mathrm{g} / \mathrm{mL}$, respectively) through primary amines of proteins and the $N$-hydroxysuccinimide (NHS) ester moiety of the Alexa Fluor 488 dye. After incubation for $2 \mathrm{~h}$ at $37^{\circ} \mathrm{C}$, the cells were washed with PBS three times, and then the slides were mounted in mounting media containing 4',6-diamidino2-phenylindole (DAPI). In our immunofluorescence experiment, cells were incubated at $37^{\circ} \mathrm{C}$ for $2 \mathrm{~h}$ with soluble HA/ FliC mixture or AuNPs-HA/FliC. Then, cells were fixed with $4 \%$ paraformaldehyde before being blocked and permeabilized with buffer containing 5\% BSA for $30 \mathrm{~min}$ at room temperature. Cells were labeled with 1:5,000 antigen-specific Abs for $1 \mathrm{~h}$, followed by 1:1,000 secondary goat DyLight ${ }^{\mathrm{TM}}$ 649 anti-mouse Ab (Biolegend, San Diego, CA, USA) for
$30 \mathrm{~min}$. Slides were washed and mounted in mounting media containing DAPI. Images were obtained with a Zeiss (LSM 700) confocal laser scanning microscope.

\section{Abs and flow cytometry}

The following Abs conjugated to fluorescein isothiocyanate (FITC), phycoerythrin (PE), and APC PerCP-Cy5.5 were used: CD11c, CD40, CD80, CD86, major histocompatibility complex (MHC) class II, $\mathrm{CD} 8 \alpha, \mathrm{CD} 3 \varepsilon$, and $\mathrm{mAb}$ isotype controls (Biolegend). After $24 \mathrm{~h}$ stimulation with prepared nanoparticles or soluble antigen/adjuvants, cells were blocked and incubated with Abs for 30 min in dark on ice. After washing twice, cells were fixed with $4 \%$ paraformaldehyde for analysis. Fixed cells were analyzed using a BD Fortessa flow cytometer (BD Biosciences, San Jose, CA, USA). Data were analyzed with the FlowJo software suite.

\section{Cytokine profile of stimulated DCs}

Cytokine production was measured by ELISA. Cells were seeded at $10^{5}$ cells/well in 96-well cell culture plates, followed by treatment with $1 \mu \mathrm{g} / \mathrm{mL} \mathrm{R} 848$ (as a positive control), soluble HA, soluble HA/FliC mixture, or proteinconjugated AuNPs for $18 \mathrm{~h}$. The final concentration of HA and FliC was $5 \mu \mathrm{g} / \mathrm{mL}$ and $1 \mu \mathrm{g} / \mathrm{mL}$, respectively. Culture supernatants were collected and tested for IL-6, IL-12, and TNF- $\alpha$ by using cytokine kits (Biolegend) following the manufacturer's protocols.

\section{In vitro stimulation of $T$ cells}

Splenic tissue from BALB/c mice was cut into small pieces and mechanically minced. After filtering through a $70 \mu \mathrm{m}$ cell strainer, cells were washed with PBS containing 5\% FBS. Cells were labeled with carboxyfluorescein succinimidyl ester (CFSE) (Thermo Fisher Scientific) as per the manufacturer's protocol. BM-derived DCs (BMDCs) were stimulated for $18 \mathrm{~h}$ with different treatments described earlier. Stimulated DCs were harvested and cocultured with CFSE-labeled splenic cells at a ratio of 1:5 (DC:splenic) for 5 days. The cells were collected and stained with PerCP/Cy5.5 anti-mouse $\mathrm{CD} 3 \mathrm{Ab}$ and $\mathrm{APC}$ anti-mouse $\mathrm{CD} 8 \mathrm{Ab}$ to measure $\mathrm{CD}^{+}$ and $\mathrm{CD}^{+} \mathrm{T}$ cell frequencies. After gating, the proliferation was measured by the loss of CFSE dye.

\section{Statistical analysis}

Statistical analysis was carried out using Student's independent $t$-test. A $P$-value of $<0.05$ was significant: ${ }^{*} P<0.05$, $* * P<0.01, * * * P<0.005$. 


\section{Results}

\section{Characterization and functionalization of proteins-coated AuNPs}

As shown in Scheme 1, two different thiol-bearing linkers, $\mathrm{SH}-\mathrm{NTA}$ and azido polyethylene glycol thiol $\left(\mathrm{N}_{3}\right.$-PEG-SH), were subsequently conjugated onto AuNPs. Then, histidinetagged trimeric HA and alkyne-functionalized FliC were covalently attached to AuNPs via the conjugated linkers by using metal-chelating and click chemistry reactions, respectively.

We chose AuNPs with a diameter of $18 \mathrm{~nm}$ as the influenza vaccine carrier and a long PEG spacer (azide-PEG-SH) as one of the protein conjugation linkers to facilitate the AuNPs co-delivery of HA and FliC while retaining the functions of the two proteins. Using TEM and DLS, we verified that our AuNPs had an $18 \mathrm{~nm}$ hydrodynamic diameter, a uniform shape, and a narrow size distribution (Figure 1A, Table 1). Our particles increased in size from $18 \mathrm{~nm}$ to $145 \mathrm{~nm}$ due to the swollen corona after PEGylation and protein conjugation, as demonstrated in Figure 1B and Table 1. The protein-conjugated AuNPs showed a negative $\zeta$-potential of $-17 \mathrm{mV}$, which may reduce the formation of aggregates in the presence of negatively charged serum proteins and could benefit for vaccine delivery during in vivo administration (Table 1).
Nanostructures can strongly scatter and/or absorb light at a resonance wavelength depending on the size and shape. This allows for the verification of particles' surface modification, size change, and the protein conjugation by evaluating the localized surface plasmon resonance (LSPR). The bare AuNPs had an LSPR peak of $518 \mathrm{~nm}$ (Figure 1C). After duallinker modification and $\mathrm{HA} / \mathrm{FliC}$ protein conjugation, the LSPR wavelength shifted to 520 and $530 \mathrm{~nm}$, respectively, with no or low peak broadening. This indicated the success of the AuNP surface modifications during the serial incubation processes. Conjugation of proteins onto AuNPs was further analyzed by gel electrophoresis. The results indicated that stable AuNPs-HA/FliC was obtained (Figure 1D). The results also showed evidence of an efficient conjugation event on AuNP surface through the dual-linker strategy. Bradford assay and band densitometry were carried out to quantify the conjugated HA and FliC (Figure S1). The amount and ratio of attached $\mathrm{HA}$ and FliC per nanoparticle could be controlled by adjusting the original proteins' concentrations and incubation volumes. After optimization, a ratio of 20:1 was used between the antigen and adjuvant.

The abilities of AuNPs-HA/FliC and soluble FliC to activate TLR5-mediated innate signaling were compared to evaluate the structural integrity and functionality of the

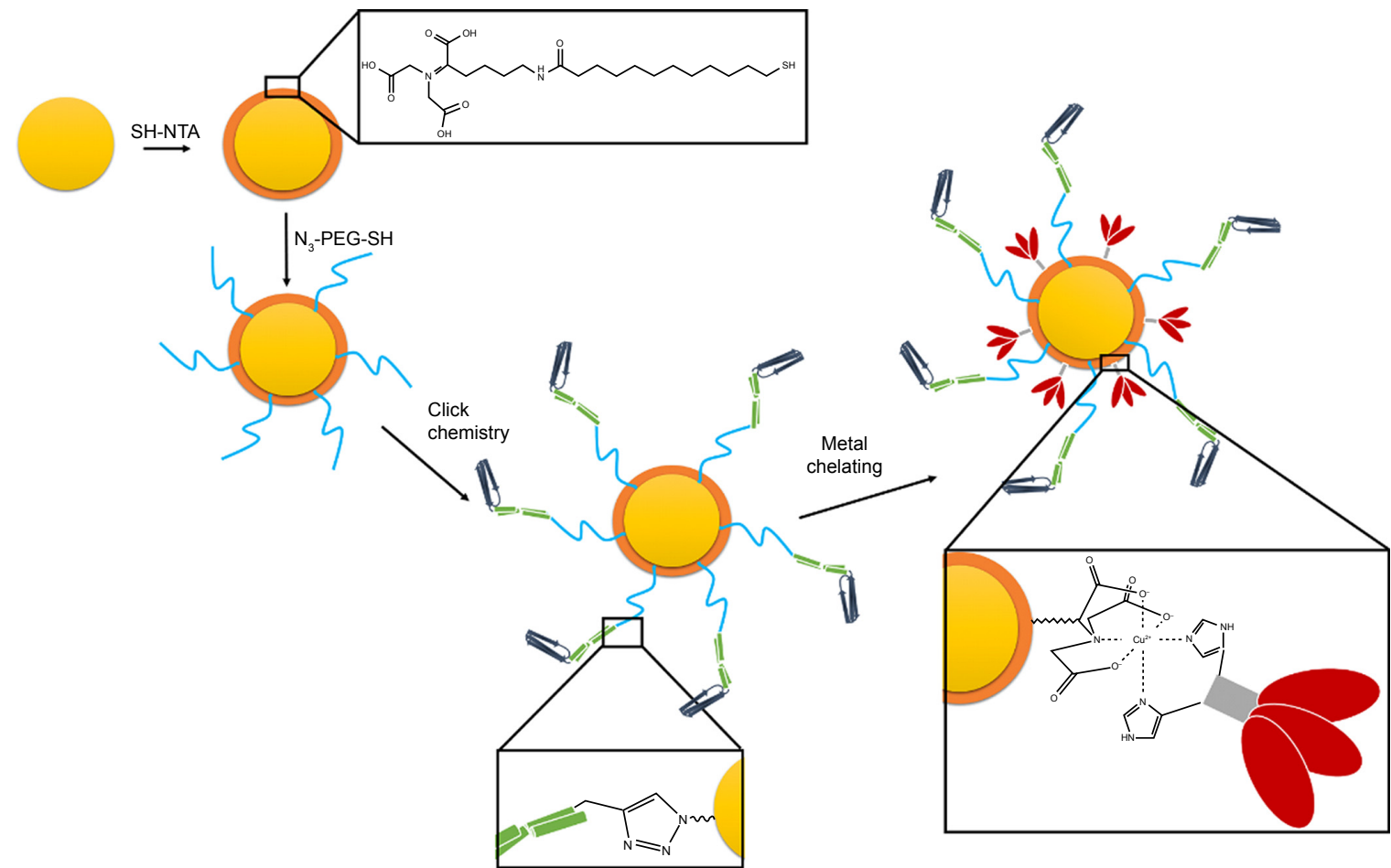

Scheme I Design of dual-linker modified AuNPs to quantitatively conjugate HA and FliC.

Abbreviations: AuNPs, gold nanoparticles; FliC, flagellin; HA, hemagglutinin; PEG, polyethylene glycol; $\mathrm{N}_{3}-\mathrm{PEG}-\mathrm{SH}$, Azido PEG thiol; SH-NTA, N-[No,N $\alpha-b i s$ (carboxymethyl)-I-lysine]-I2-mercaptododecanamide. 


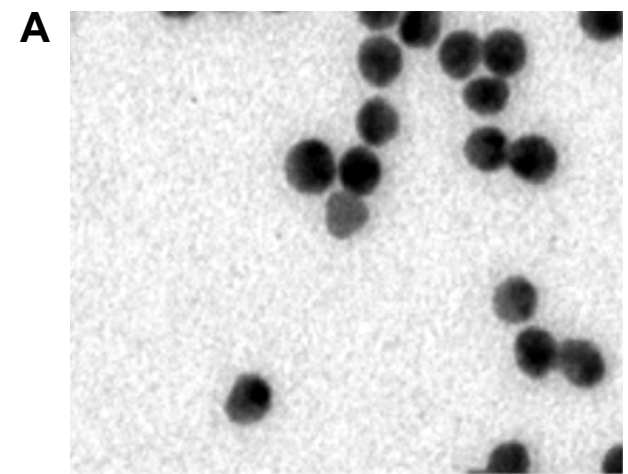

B
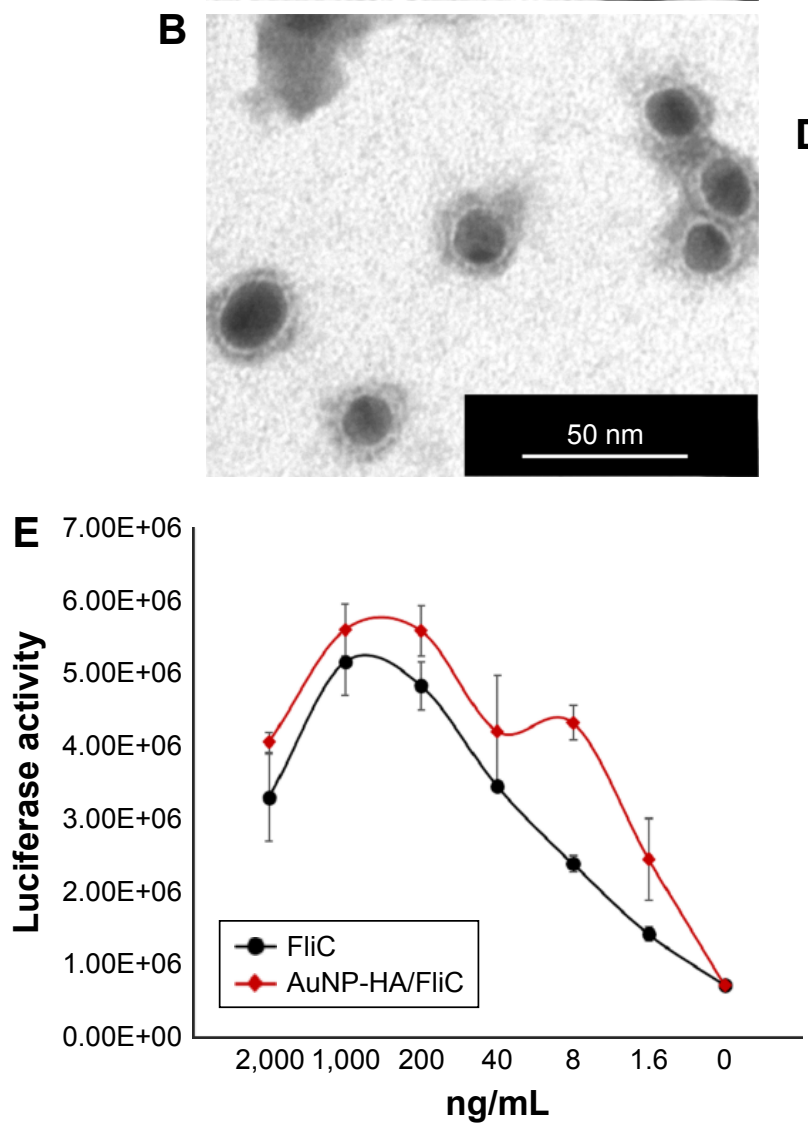

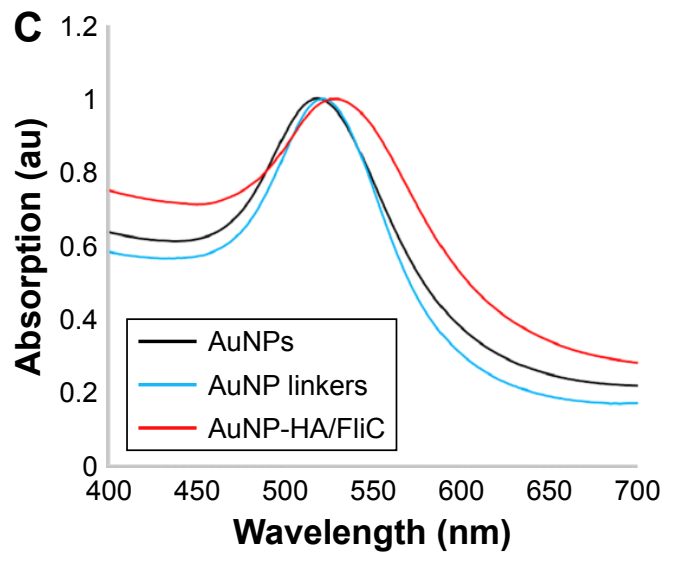

D
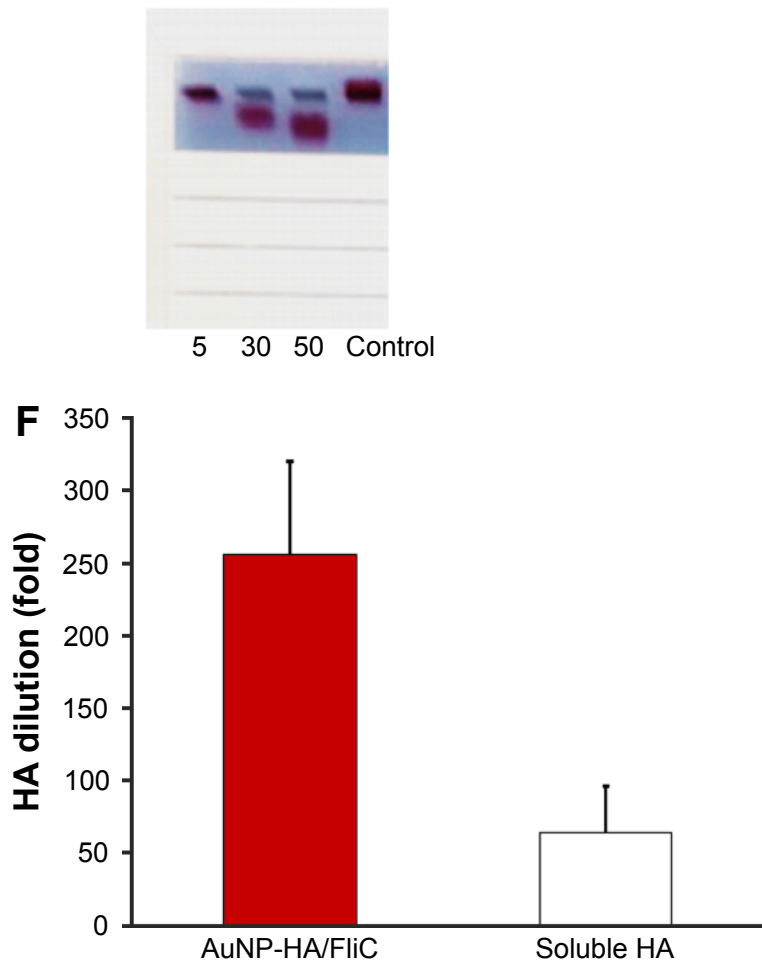

Figure I Characterization of HA and FliC protein-functionalized AuNP.

Notes: (A, B) Transmission electron micrographs of AuNPs and HA/FliC-modified AuNPs. (C) UV-visible absorption spectra of bare AuNPs, dual-linker modified AuNPs, and HA/FliC-conjugated AuNPs. (D) Agarose gel electrophoresis of different amount of proteins conjugated to the same amount of AuNPs. The direction of migration is top to bottom. Lane I, $5 \mu \mathrm{g} / 0.4 \mathrm{mg}$; lane 2, $30 \mu \mathrm{g} / 0.4 \mathrm{mg}$; lane 3, $50 \mu \mathrm{g} / 0.4 \mathrm{mg}$; lane 4, bare AuNPs. (E) TLR5-specific bioactivity of AuNP-HA/FliC and soluble FliC. (F) HA titers in AuNP-HA/FliC and soluble HA protein. A and $\mathbf{B}$ share the same scale bar.

Abbreviations: AuNP, gold nanoparticle; FliC, flagellin; HA, hemagglutinin; UV, ultraviolet.

Table I DLS data and conjugated protein profile of HA/FliC-modified AuNPs

\begin{tabular}{llllll}
\hline Sample & $\begin{array}{l}\zeta \text {-potential } \\
(\mathbf{m V})\end{array}$ & $\begin{array}{l}\text { Average } \\
\text { size } \mathbf{( n m})\end{array}$ & PDI & $\begin{array}{l}\text { Band density } \\
\text { (HA/FliC, } \mu \mathrm{g} / \mathbf{m L})\end{array}$ & $\begin{array}{l}\text { Bradford assay } \\
(\mathbf{H A} / \mathbf{F l i C}, \mu \mathbf{g} / \mathbf{m L})\end{array}$ \\
\hline AuNPs-HA/FliC & $-16.8 \pm 3.1$ & $145 \pm 5.8$ & $0.633 \pm 0.122$ & $160 / 8$ & 192 \\
AuNPs-HA & $-17.5 \pm 1$ & $106 \pm 3$ & $0.413 \pm 0.138$ & 90 & 98 \\
AuNPs linkers & $-20.8 \pm 0.5$ & $96 \pm 3.6$ & $0.28 \pm 0.109$ & - & - \\
AuNPs & $-34 \pm 0.4$ & $18.3 \pm 1.2$ & $0.168 \pm 0.116$ & - & - \\
\hline
\end{tabular}

Abbreviations: AuNPs, gold nanoparticles; DLS, dynamic light scattering; FliC, flagellin; HA, hemagglutinin; PDI, polydispersity index. 
conjugated FliC (Figure 1E). AuNPs-HA/FliC and soluble FliC stimulated target cells to produce a comparable level of TLR5 innate signal as demonstrated by their similar reporter luciferase activities. A hemagglutination activity assay was performed for both AuNPs-HA/FliC and soluble HA to determine whether the conjugated HA protein retained its natural conformation and activity. AuNPs-HA/FliC showed fourfold higher activity versus soluble HA in agglutinating turkey red blood cells, demonstrating the multivalence of HA on nanoparticle surfaces, as shown in Figure 1F.

\section{Humoral responses to AuNPs-HA/FliC vaccines}

The humoral immune response against influenza viral antigen was determined for mice with different immunization strategies (Table S1). As shown in Figure 2, AuNPs-HA/FliC induced a strong IgG response after a single immunization by IN route $(823 \pm 156 \mathrm{ng} / \mathrm{mL})$ when compared to the mixture of soluble HA/FliC $(283 \pm 91 \mathrm{ng} / \mathrm{mL}, P<0.005)$ or AuNPs-HA $(433 \pm 96 \mathrm{ng} / \mathrm{mL}, P<0.005)$ treatments. These results suggest that AuNPs-HA/FliC can boost $\mathrm{Ab}$ responses and highlight the potential of HA and FliC-dual-conjugated AuNPs as an alternative to conventional influenza vaccines..$^{22,23}$

\section{Cellular uptake of HA/FliC-dual- conjugated AuNPs by DCs}

DC cytokine release and antigen processing for presentation to $\mathrm{T}$ cells are essential in triggering adaptive immune responses. ${ }^{24} \mathrm{We}$ implemented in vitro studies to investigate

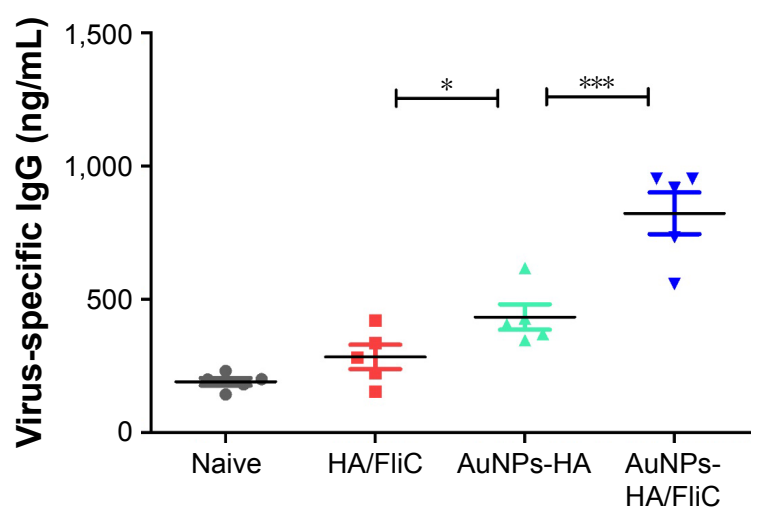

Figure 2 Systemic $\lg G$ immune responses.

Notes: Mice were immunized intranasally with different AuNP formulations containing $5 \mu \mathrm{g}$ of $\mathrm{HA}$ and $0.25 \mu \mathrm{g}$ of FliC. Blood samples were collected at day 21 post vaccination. ELISA plates were coated with $4 \mu \mathrm{g} / \mathrm{mL}$ of A/Aichi/2/68 virus. HRP-conjugated goat anti-mouse $\lg G$ was used for detection. Significant difference: $* \mathrm{p}<0.05$; *** $\mathrm{P}<0.005$ (mean $\pm \mathrm{SEM}, \mathrm{n}=5$ ).

Abbreviations: AuNPs, gold nanoparticles; FliC, flagellin; HA, hemagglutinin. whether the strong humoral immune responses of the AuNP formulation are related to the activation of DCs.

DC targeting and internalization are important for an effective vaccine platform. Spherical nanoparticles have shown high potentials to be phagocytosed by DCs. ${ }^{25,26}$ Accordingly, we investigated the uptake efficiency of AuNPs into DCs. AuNPs-HA/FliC and AuNPs-HA were modified with a fluorophore (Alexa Fluor 488, AF488) through NHS-amine bonding between the dye and proteins. AF488 labeled AuNPs ( $5 \mu \mathrm{g} / \mathrm{mL}$ HA and $0.25 \mu \mathrm{g} / \mathrm{mL}$ FliC) were incubated with BMDCs for $2 \mathrm{~h}$ and then analyzed by confocal fluorescence microscopy. As shown in Figure 3A and $\mathrm{B}$, the AuNPs-HA/FliC treatment showed considerable fluorescence signal while slightly less fluorescent intensity was observed in the AuNPs-HA treatment. To confirm the targeting difference between the two treatments, a quantitative evaluation was conducted using flow cytometry (Figure 3C and D). AuNPs-HA/FliC exhibited a stronger mean fluorescence intensity (MFI) compared to AuNPs-HA. Particles in the cytoplasm could also be demonstrated using TEM (Figure S2). Besides phagocytosis, cytosolic delivery of antigen/adjuvant-conjugated AuNPs may help to promote the activation of the inflammatory caspase pathway and $\mathrm{MHC}$ class I epitope loading. ${ }^{27,28}$

To evaluate whether the HA antigen was effectively delivered into DCs by AuNPs, an immunofluorescence assay was used to confirm the specificity and function of the conjugated antigens. JAWS II cells were treated with AuNPs-HA/ FliC or soluble HA/FliC for $12 \mathrm{~h}$. We found that AuNPs-HA/ FliC could significantly enhance the antigen uptake efficacy of DCs (Figure 3E). In contrast, weak signal was detected in cells treated with the mixture of soluble HA/FliC (Figure 3F). Overall, these results reveal that antigen/adjuvant-conjugated AuNPs can be readily taken in by DCs, at least partially via receptor (TLR5)-mediated endocytosis.

\section{Evaluation of proinflammatory cytokines and costimulatory surface markers in murine BMDCs and JAWS II cells treated with AuNPs-HA/FliC}

The regulation of adaptive immunity by TLR agonists is dependent on the release of relative cytokines by stimulated DCs. These cytokines facilitate the differentiation of appropriate CD4 Th subsets. Quantitative ELISA of IL-12p40, IL-6, and TNF- $\alpha$ was performed after $18 \mathrm{~h}$ stimulation of murine BMDCs and JAWS II cells with various concentrations of 
A

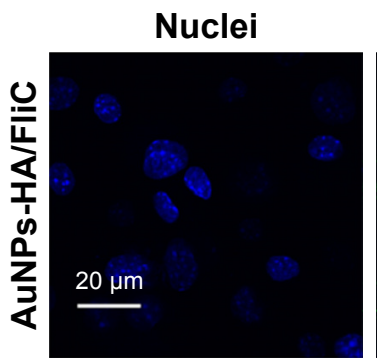

B

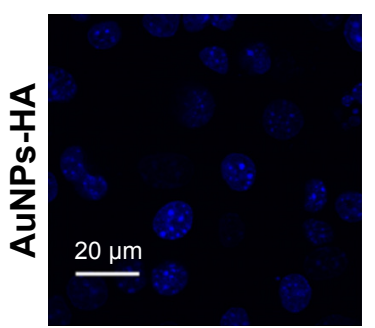

C

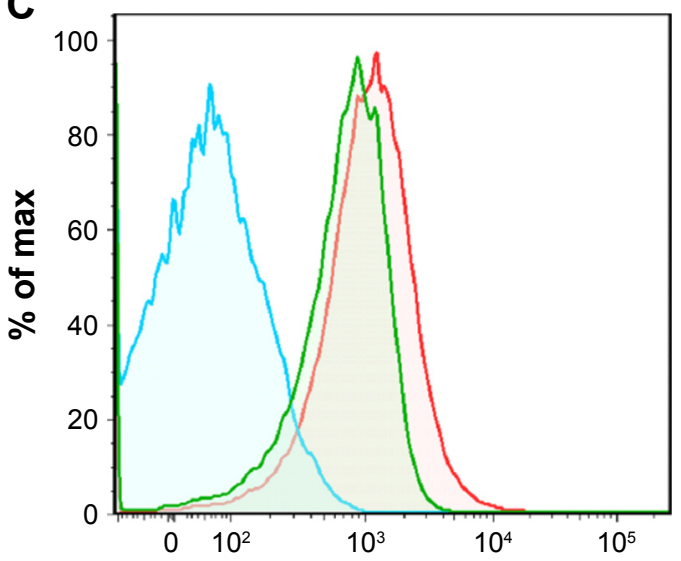

AuNPs-HA/FliC
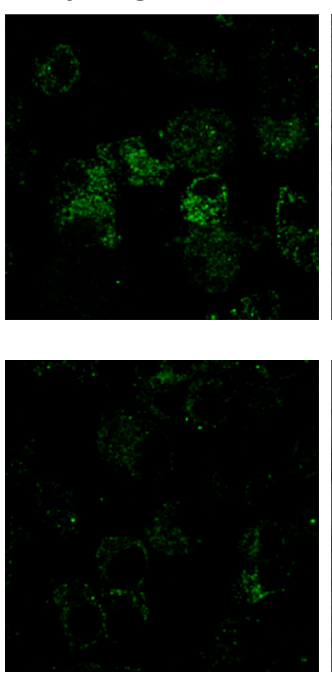

TL

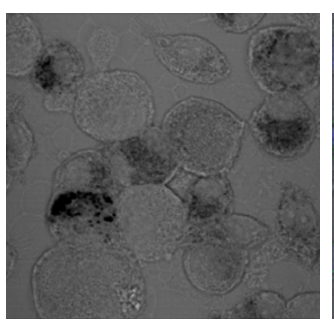

Merge
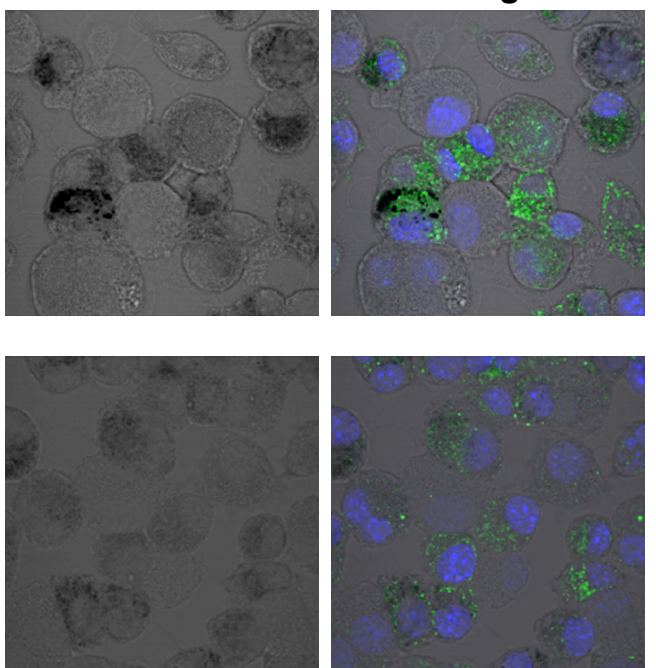

D 1,500

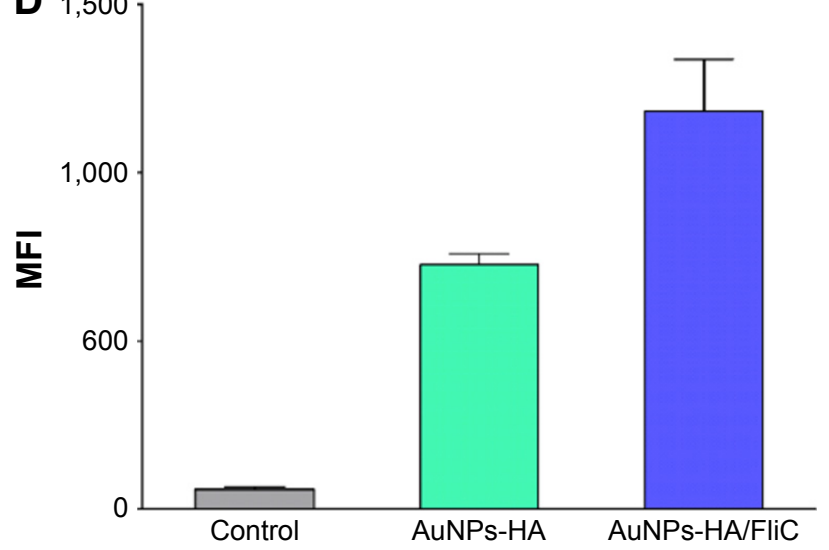

E
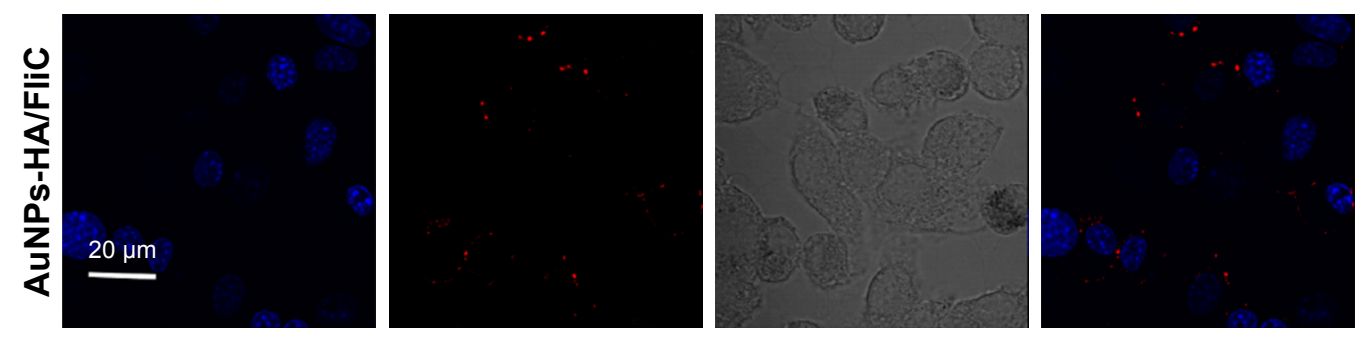

$\mathbf{F}$
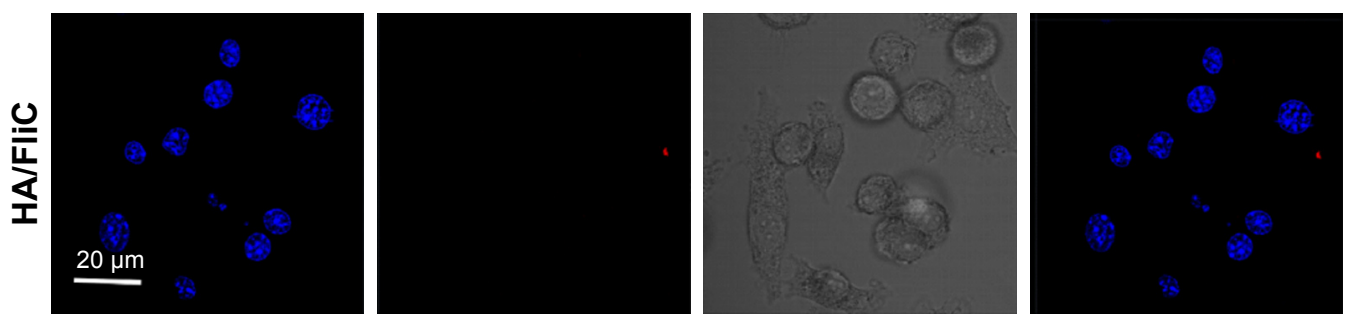

Figure 3 Uptake of AuNPs-HA/FliC in vitro.

Notes: (A, B) CLSM image of BMDCs incubated with Alexa 488-labeled AuNPs-HA/FliC or AuNPs-HA for $2 \mathrm{~h}$. Nanoparticles were recognized as black dots in the bright field and merge images. The nucleus was stained blue with DAPI. (C) After $18 \mathrm{~h}$ incubation with BMDCs, cells were analyzed for CDIIc ${ }^{+}$and Alexa $488^{+}$cell frequencies using FACS. Blue: control; green: AuNPs-HA; red: AuNPs-HA/FliC. (D) Quantitative analysis of uptake efficacy of AuNPs-HA and AuNPs-HA/FliC by BMDCs. The Y-axis is MFI of Alexa 488 after gating of CDIIc cells, ns: $P>0.05$. (E, F) CLMS immunofluorescence images of JAWS II treated with AuNPs-HA/FliC or soluble HA/FliC for $12 \mathrm{~h}$. Cells were then fixed and treated with Aichi-positive sera and DyLight ${ }^{\mathrm{TM}} 649$ anti-mouse $\operatorname{lgG} \mathrm{Ab}$. HA was recognized by fluorescent-labeled Ab (red). Nuclei were stained by DAPI (blue). The concentrations used in treatments were $5 \mu \mathrm{g} / \mathrm{mL}$ of HA and $0.5 \mu \mathrm{g} / \mathrm{mL}$ of FliC.

Abbreviations: Ab, antibody; AuNPs, gold nanoparticles; BMDCs, bone marrow-derived dendritic cells; CLSM, confocal laser scanning microscopy; DAPI, 4',6-diamidino2-phenylindole; FliC, flagellin; HA, hemagglutinin; MFI, mean fluorescence intensity; ns, no significance; TL, transmitted light. 
AuNPs-HA/FliC, AuNPs-HA, soluble HA, or mixture of soluble HA/FliC. To obtain sufficient maturation, the concentration of FliC was increased to $1 / 5 \mathrm{w} / \mathrm{w}$ of HA.

As shown in Figure 4, AuNPs-HA/FliC induced significantly higher levels of IL-6 (4,055 $\pm 514 \mathrm{pg} / \mathrm{mL})$ and

BMDCs
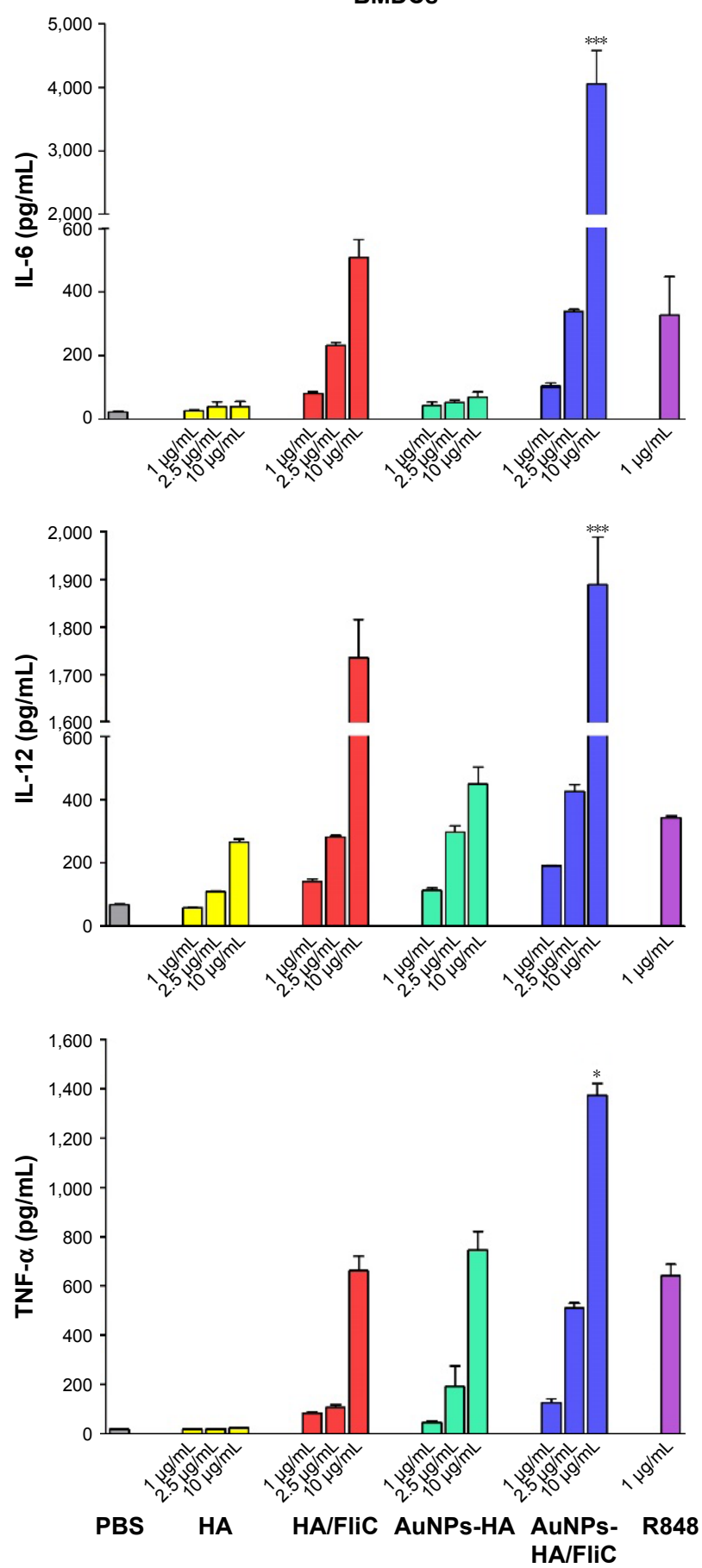

TNF- $\alpha(1,379 \pm 49 \mathrm{ng} / \mathrm{mL})$ than the mixture of soluble HA/ FliC $(512 \pm 53$ and $662 \pm 58 \mathrm{ng} / \mathrm{mL}$, respectively, $P<0.01)$ in the BMDC model. Similarly, in the JAWS II cell model, AuNPs-HA/FliC evoked higher TNF- $\alpha$ expression $(6,780 \pm 277 \mathrm{ng} / \mathrm{mL})$ than the mixture of soluble $\mathrm{HA} / \mathrm{FliC}$
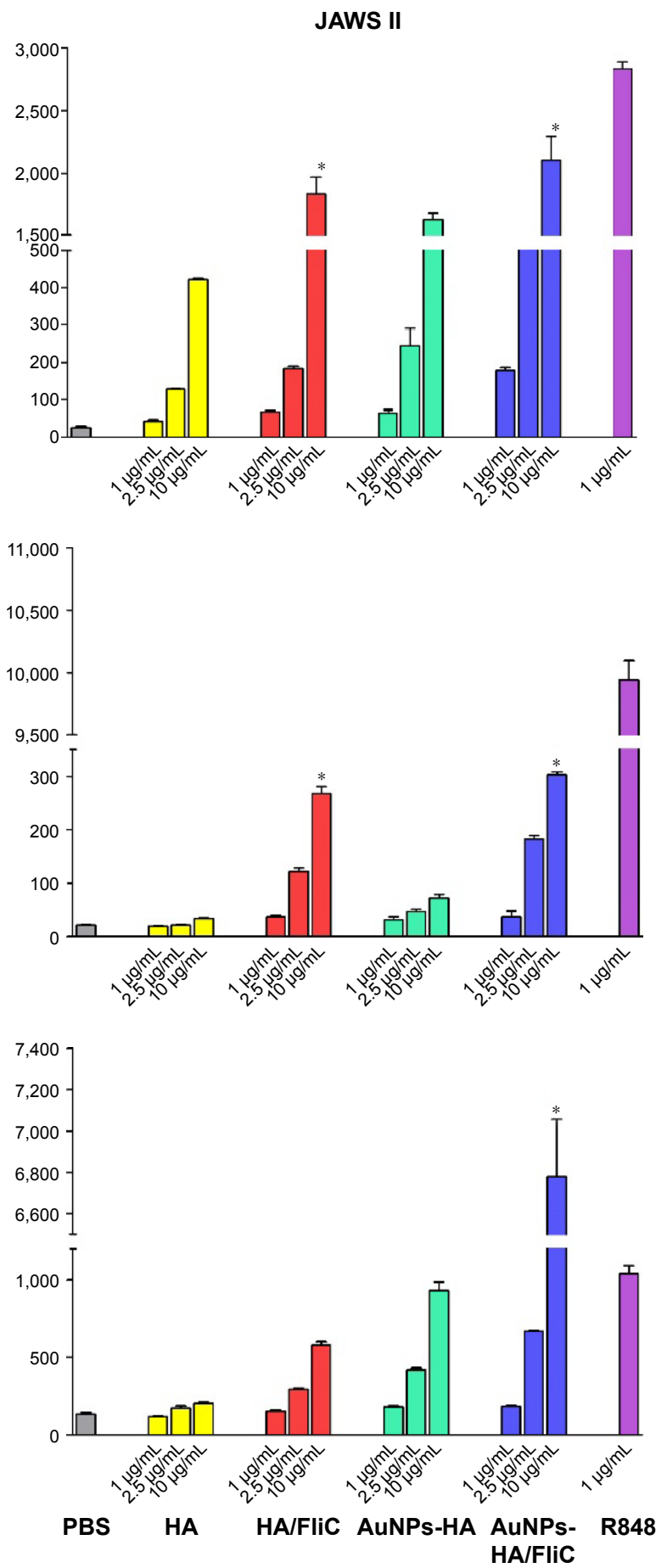

Figure 4 Cytokines produced by JAWS II cells and BMDCs stimulated with different AuNP formulations or PBS.

Notes: Cells were treated with soluble HA, soluble HA/FliC, AuNPs-HA, or AuNPs-HA/FliC at various HA and FliC concentrations. The concentration indicated in the figure was conjugated HA concentration. The ratio between HA and FliC was 5:I (w/w). R848 was used as positive control $(I \mu g / m L)$. Significant difference: $* P<0.05$, $* * * P<0.005$ versus control (mean $\pm \mathrm{SEM}, \mathrm{n}=2-3$ )

Abbreviations: AuNPs, gold nanoparticles; BMDCs, bone marrow-derived dendritic cells; FliC, flagellin; HA, hemagglutinin; IL, interleukin; SEM, standard error of the mean; PBS, phosphate buffered saline. 
$(579 \pm 22 \mathrm{ng} / \mathrm{mL}, P<0.005)$ and AuNPs-HA $(201 \pm 8 \mathrm{ng} / \mathrm{mL}$, $P<0.001)$ as well. However, significant enhancement of AuNPs-HA/FliC could only be observed at $2.5 \mu \mathrm{g} / \mathrm{mL}$ treatment for IL-6 expression. For the $10 \mu \mathrm{g} / \mathrm{mL}$ treatment, both AuNPs-HA/FliC and the mixture of soluble HA/FliC showed comparable IL-6 secretion. The secretion levels of IL-12p40 stimulated by AuNPs-HA/FliC and mixture of soluble HA/FliC were also comparable $(P>0.05)$. In addition, AuNPs-HA stimulated more TNF- $\alpha$, but less IL- 6 and IL-12p40 production than the mixture of soluble HA/FliC in both cell models.

The maturation efficacy of BMDCs and JAWS II cells by AuNPs-HA/FliC or soluble antigens and adjuvants was compared by measuring the expression of cell surface markers MHC class II, CD80, CD86, and CD40. As shown in Figure 5, the maximal upregulation of all markers was found in the AuNPs-HA/FliC stimulation group. In contrast, the mixture of soluble antigen/adjuvant induced significantly weaker responses of CD40 ( $P<0.05$ in JAWS II cells), CD80 $(P<0.05$ in BMDCs), and CD86 $(P<0.01$ in BMDCs; $P<0.05$ in JAWS II cells). Consistent with the cytokine secretion results, soluble HA/FliC $(12,200 \pm 830 \mathrm{MFI})$ triggered more expression of CD80 than AuNPs-HA (7,998 \pm 302 MFI, $P<0.05)$. This suggested that FliC, as an adjuvant, played an essential role in activating DCs. However, antigen conjugate particulates performed better in stimulating B cells and enhanced humoral immune responses.

Our results demonstrate that the simultaneous delivery of antigens and adjuvants by dual-conjugated AuNPs has the strong potential to prompt DCs to mature into potent APCs capable of initiating adaptive immune responses.

\section{T cell proliferation induced by AuNPs- HA/FliC-primed BMDCs}

Accumulating evidence has demonstrated that a nanoparticlebased vaccine platform can improve immune responses due to its similarity of composition and pattern of surface structures to natural pathogens/viruses. ${ }^{29}$ We have demonstrated that AuNPs-HA/FliC can induce strong antigen-specific B cell responses as described earlier. An effective vaccine should also induce robust $\mathrm{T}$ cell-mediated immune responses, especially cytotoxic $\mathrm{CD} 8^{+} \mathrm{T}$ cells, for viral infection control. However, most subunit vaccines elicit poor $\mathrm{CD} 8^{+}$ $\mathrm{T}$ responses owing to the low efficiency of cross-presentation of antigens.

To further demonstrate the possible mechanisms involved in the enhanced immune responses seen, BMDCs were used to test whether AuNPs-HA/FliC can facilitate DC maturation resulting in $\mathrm{T}$ cell proliferation. As shown in Figure 6A and $\mathrm{C}$, AuNPs-HA/FliC-primed DCs significantly facilitated splenic $\mathrm{T}$ lymphocytes proliferation compared to the other formulations. The $\mathrm{CD}^{+}$population was $19.5 \%$ in cocultured splenic lymphocytes with AuNPs-HA/FliC-primed DCs versus $8.82 \%$ with the mixture of HA/FliC-primed DCs $(P<0.01)$ and $7.17 \%$ with AuNPs-HA primed DCs $(P<0.01)$. Interestingly, AuNPs-HA demonstrated a comparable capacity to that of the mixture of soluble $\mathrm{HA} / \mathrm{FliC}$ in priming DCs to facilitate $\mathrm{T}$ cell proliferation $\left(7.17 \%-8.82 \%\right.$ for $\mathrm{CD}^{+}$frequency, respectively; $P>0.05$ ). To further distinguish between CD8 and $\mathrm{CD} 4$ cell contribution in the observed $\mathrm{T}$ cell proliferation $\left(\mathrm{CD}^{+}\right.$cells), $\mathrm{CD}^{+}$cells were gated. As shown in Figure 6B and $\mathrm{C}, \mathrm{CD} 8 \mathrm{~T}$ cell frequency had the same trend but was much lower than total $\mathrm{T}$ cells $\left(\mathrm{CD}^{+}\right.$cells). The AuNPs-HA/

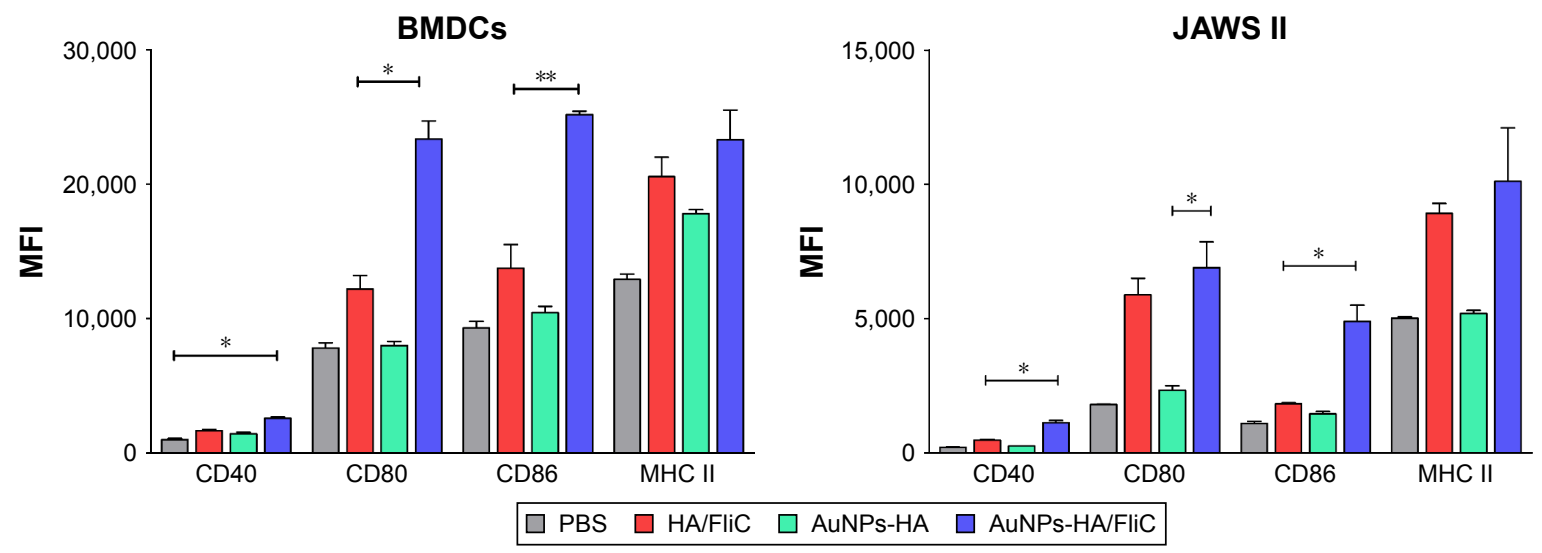

Figure 5 Maturation of BMDCs and JAWS II cells.

Notes: Costimulatory molecules CD40, CD80, CD86, and MHC class II on CDI lc ${ }^{+}$BDMCs and JAWS II cells treated with PBS (gray), HA/FliC (red), AuNPs-HA (green), and AuNPs-HA/FliC (blue) were compared by FACS. The MFI on CDI I c gated cells were indicated. Significant difference: $* P<0.05$; $* * P<0.0 I$ (mean \pm SEM, $n=2-3$ ). Abbreviations: AuNPs, gold nanoparticles; BMDCs, bone marrow-derived dendritic cells; FACS, fluorescence activated cell sorting; FliC, flagellin; HA, hemagglutinin; MFI, mean fluorescence intensity; MHC, major histocompatibility complex; SEM, standard error of the mean. 

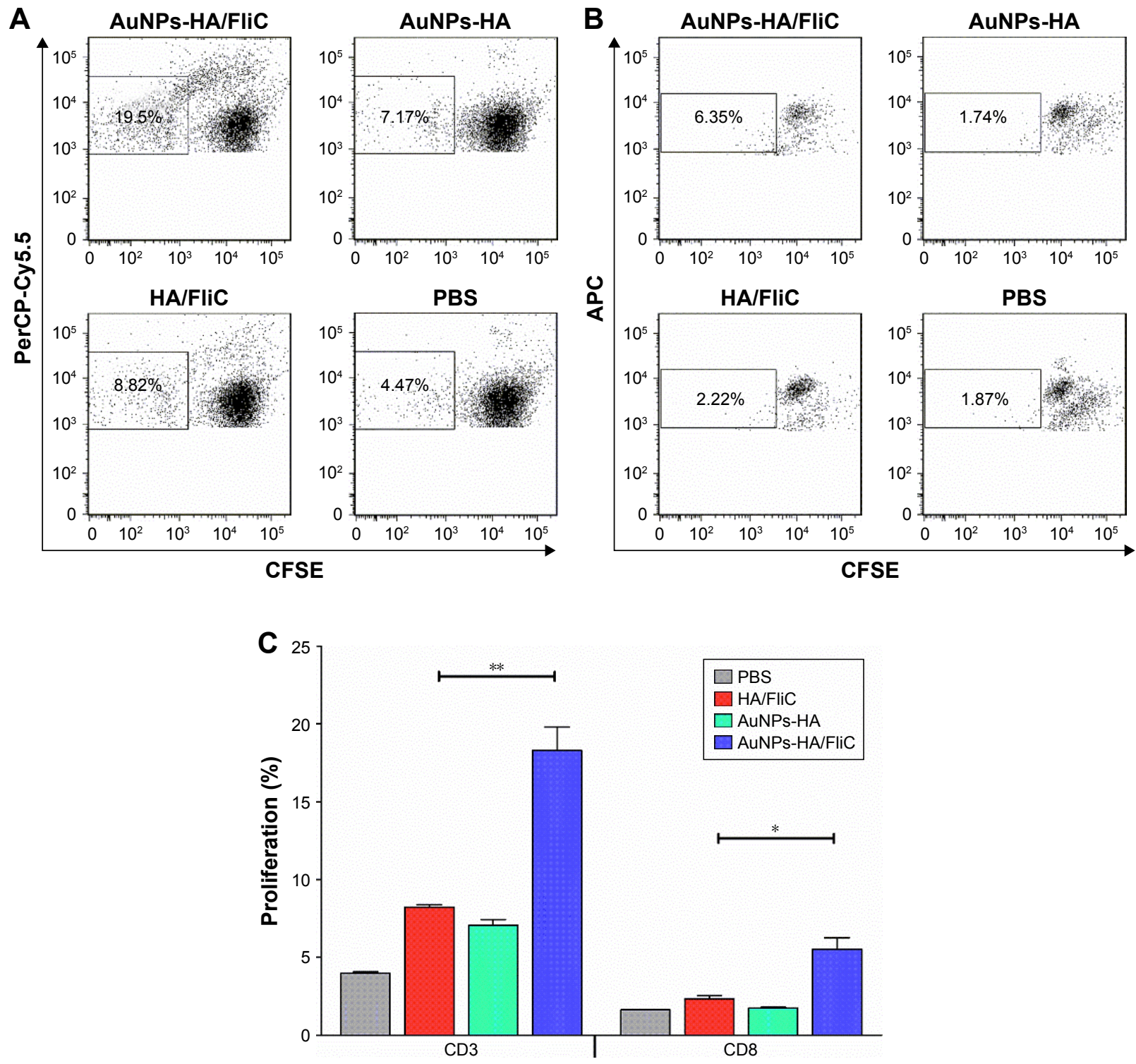

Figure 6 AuNPs-HA/FliC enhanced antigen presentation by BMDCs and stimulation of $\mathrm{CD}^{+}$and $\mathrm{CD}^{+} \mathrm{T}$ cells.

Notes: CFSE-labeled splenic cells were cocultured with stimulated BMDCs (DC: splenic cell ratio is 1:5). Five days later, the proliferation of CFSE-positive CD3 and CD8 cells was analyzed by flow cytometry. After blocking, cells were stained with APC-conjugated anti-CD8 $\alpha$ and PerCP-Cy5.5-conjugated anti-CD3E. (A) Representative dot plots of $\mathrm{CD}^{+} \mathrm{T}$ cell proliferation. (B) Representative dot plots of $\mathrm{CD} 8^{+} \mathrm{T}$ cell proliferation. (C) Percentages of CD3 and CD8 positive. Significant difference: $* P<0.05$; $* * P<0.01$ (mean \pm SEM, $\mathrm{n}=2-3$ ).

Abbreviations: APC, antigen-presenting cell; AuNPs, gold nanoparticles; BMDCs, bone marrow-derived dendritic cells; CFSE, carboxyfluorescein succinimidyl ester; DC, dendritic cell; FliC, flagellin; HA, hemagglutinin; SEM, standard error of the mean; PBS, phosphate buffered saline.

FliC-primed DCs activated $6.35 \%$ of $\mathrm{CD}^{+}$cells, the mixture of HA/FliC-primed DCs activated $2.22 \%$ and the AuNPs-HA activated $1.87 \%(P<0.05)$. Considering the differences of the $\mathrm{CD}^{+}$and $\mathrm{CD}^{+}$cell frequencies mentioned earlier, it is evident that the $\mathrm{CD}^{+} \mathrm{T}$ cell populations have a similar trend as that of $\mathrm{CD}^{+}$cells upon stimulation by AuNPs-HA/FliC. These data demonstrate that AuNPs-HA/FliC significantly facilitates DC maturation and in turn activates $\mathrm{T}$ cell proliferation, including both $\mathrm{CD}^{+}$and $\mathrm{CD}^{+} \mathrm{T}$ cell proliferation and differentiations.

\section{Discussion}

The advantages of subunit influenza vaccines over conventional flu vaccines include egg-independent production, shorter production periods, and a low biosafety level requirement for production facilities. However, the immunogenicity of subunit vaccines can be compromised due to poor endosomal delivery into APCs. To overcome this weakness, conjugated nanoparticles were studied to improve the efficacy and immunogenicity of influenza subunit vaccines. Viruslike particles (VLPs) composed of single or multiple viral 
antigens have been studied as novel vaccination candidates because they induce potent $\mathrm{Ab}$ responses and provide heterosubtypic cross-protection from morbidity and mortality. ${ }^{30,31}$ However, concerns remain such as low production efficiency and potential cytotoxicity. Liposomes have shown a superior ability to deliver multiple antigens and adjuvants to the targeting sites, although their poor stability and loading efficiency limit their benefits in vaccination development. ${ }^{32,33}$ Compared to liposomes, AuNPs are better suited as a vaccine carrier. First, because they are immunologically inert, AuNPs will not induce carrier-specific immunity which may diminish the efficacy of a vaccine in subsequent immunizations with the same carrier. Second, unlike replicating vaccine vectors and attenuated vaccines which may possess the risk of potential reversion to a virulent form, AuNPs present no similar safety concerns. In addition, the high stability of AuNPs makes conjugated AuNPs vaccines promising for safe storage and quick distribution without a cold chain. ${ }^{34}$ This is particularly important in responding to an emerging influenza pandemic when the resources of public health facilities and delivery chains are limited or strained.

Yet, despite numerous studies focused on the use of AuNPs as antigen carriers to enhance immunostimulatory efficiency, the results to date may not be sufficient to support the widespread use of an AuNP-based subunit vaccine. This might be explained by conformational changes of the antigens and/or adjuvants when conjugated to the nanoparticles. ${ }^{34,35}$ In many cases, the low stability of nanoparticles and the low conjugation efficacy of antigenic protein/peptide on the surfaces of nanoparticles also contribute to the insufficient immune efficacy. We chose two facile and effective means, metal chelating and click chemistry, to separately conjugate HA and FliC on the same AuNPs with high coupling specificity and quantity compared to other common surface modification methods (Table S2 and Figure S3). In addition, these two coupling methods can help mitigate undesired cross-linking and control the physical orientation of HA protein on the nanoparticle surfaces, improving the immunogenicity of the antigens.

$\mathrm{CD}^{+} \mathrm{T}$ cells are critical for inducing high-affinity antigen-specific $\mathrm{Ab}$ responses. ${ }^{36}$ In the current study, HA and FliC dual-conjugated AuNPs were found to induce the greatest $\mathrm{Ab}$ responses, which indicated that $\mathrm{CD}^{+} \mathrm{T}$ cells were effectively primed by dual-conjugated AuNPs. A much higher frequency of CD3 population than $\mathrm{CD}^{+}$cells in splenocytes stimulated by AuNPs-HA/FliC-primed DCs indicates robust $\mathrm{CD}^{+}$cell proliferation and differentiation as well. Cross-linking multiple immunoglobulins on naïve
B cell surface by multivalent antigens has been demonstrated to contribute to a strong $\mathrm{Ab}$ response. ${ }^{23,37}$ The capacity for inducing strong humoral immune responses by AuNPs-HA in the absence of coadministrated adjuvant could be a benefit of the highly repetitive HA on the surface of the particles. Meanwhile, the particulate itself can improve the DC's targeting and antigen internalization efficiency. Furthermore, the particulate delivery of FliC may contribute to $\mathrm{B}$ cell activation by directly triggering TLR5 signaling on B cells since B cells also express and respond to TLRs. ${ }^{38,39}$ The advantages of AuNPs as a vaccine platform make the nanoparticle an outstanding self-adjuvanting system. This system also benefits from dose sparing because of their stability of the particles (resistant to proteolysis) versus the soluble protein antigens. ${ }^{7,40}$ Thus, AuNPs-HA/FliC is a highly immunogenic system for vaccine delivery. Antigen/adjuvant dual-conjugated AuNPs could be developed into a vaccine platform for different diseases.

We observed that DCs produced high levels of proinflammatory cytokines when stimulated by AuNPs-HA/ FliC, indicating that the simultaneous delivery of antigen and adjuvant by AuNPs accelerated the maturation of DCs. Consistent with recent observations, the effective intracellular uptake of nanoparticles is essential to improving the maturation of DCs. Furthermore, the multivalent display on the particles' surface might be another important factor in the promotion of the DCs activation. Interestingly, the induction of TNF- $\alpha$, stimulated by AuNPs-HA, was stronger than the dissolved formulation, while the IL-12p40 secretion level was not. It was known that IL-12p40 is secreted as a product of TLR-mediated signals, which uses MyD88 as the immediate downstream component in the signaling transduction pathways. The increase in TNF- $\alpha$, but not IL-12p40, may indicate that the presence of HA on particles allows a broad and nonspecific receptor-ligand interaction and enhances the production of TNF- $\alpha$. It is known that HA in influenza virions function as ligands to bind to sialic acid-containing receptors on host respiratory endothelium cell surfaces to initiate a cell infection. ${ }^{41,42}$ These results suggest that nanoparticles or antigen-onlycoated nanoparticles may induce an indirect sensing by DCs which provokes their maturation and the subsequent immune response.

For an ideal viral vaccine, it is important to stimulate cellular immunity, which is required for a long-lasting and specific immunological memory response against infections. ${ }^{24}$ $\mathrm{CD}^{+}$and $\mathrm{CD}^{+} \mathrm{T}$ cells express clonally distributed receptors that recognize antigenic epitopes loaded onto $\mathrm{MHC}$ 
class I and II molecules after exogenous antigen intracellular transport and degradation in APCs. Different from the MHC class II antigen-processing pathway, MHC class I normally presents cytosolic antigens, which are degraded by proteasome and then translocated into the endoplasmic reticulum (ER) by the transporter associated with antigen processing (TAP). ${ }^{36}$ Pioneering works showed that particulate delivery of antigens or both antigens and adjuvants strongly increased the efficiency of antigenic epitopes presentation with both MHC II and MHC I pathways. ${ }^{28,43,44}$ Our data demonstrates that dual-conjugated antigen-adjuvant AuNPs are capable of accelerating antigen uptake through phagocytosis and somehow favor cytosolic delivery for downstream antigen cross-presentation through the MHC I pathway. This is an important feature for some viral vaccines because a robust CD8 T cell-mediated cytotoxic killing response can terminate viruses that have successfully escaped host extracellular immunity and infected target cells.

As mentioned, AuNPs have been reported in literature as both nontoxic and toxic. The controversy may arise from the various stabilizers and surface modifiers of the AuNPs. For example, AuNPs stabilized by citrate,,${ }^{9,10}$ biotin,,${ }^{10}$ or lysine ${ }^{11}$ were more biocompatible and did not show toxicity to mammalian cells at a maximum concentration up to $250 \mathrm{mM}$ (about $50 \mathrm{ppm}$ ).

\section{Conclusion}

By utilizing two different effective coupling reactions (metal chelating and click chemistry), we designed a highly dense and multivalent antigen-adjuvant co-delivery platform based on AuNPs. Our data advocate that antigens and adjuvants co-delivered via AuNPs can enhance antigen-specific $\mathrm{Ab}$ production, promote the maturation of DCs for antigen processing and presentation, and facilitate antigen-specific T cell-mediated immunity.

\section{Acknowledgments}

We are thankful to the core facilities in Georgia State University for their assistance with the electron micrograph, confocal micrograph, and flow cytometry studies. The study was supported by the National Institute of Allergy and Infectious Diseases of the NIH under award numbers R01AI101047 and R01AI116835. The content is solely the responsibility of the authors and does not necessarily represent the official views of the NIH.

\section{Disclosure}

The authors report no conflicts of interest in this work.

\section{References}

1. Bodewes R, Fraaij PLA, Kreijtz JHCM, et al. Annual influenza vaccination affects the development of heterosubtypic immunity. Vaccine. 2012;30(51):7407-7410.

2. Blackburne BP, Hay AJ, Goldstein RA. Changing selective pressure during antigenic changes in human influenza H3. PLoS Pathog. 2008; 4(5):e1000058.

3. Denis J, Acosta-Ramirez E, Zhao Y, et al. Development of a universal influenza A vaccine based on the M2e peptide fused to the papaya mosaic virus (PapMV) vaccine platform. Vaccine. 2008;26(27-28): 3395-3403.

4. Dykman L, Khlebtsov N. Gold nanoparticles in biomedical applications: recent advances and perspectives. Chem Soc Rev. 2012;41(6): 2256-2282.

5. Knuschke T, Bayer W, Rotan O, et al. Prophylactic and therapeutic vaccination with a nanoparticle-based peptide vaccine induces efficient protective immunity during acute and chronic retroviral infection. Nanomedicine. 2014;10(8):1787-1798.

6. Wang B-Z, Quan F-S, Kang S-M, Bozja J, Skountzou I, Compans RW. Incorporation of membrane-anchored flagellin into influenza virus-like particles enhances the breadth of immune responses. $J$ Virol. 2008; 82(23):11813-11823.

7. Moon JJ, Suh H, Li AV, Ockenhouse CF, Yadava A, Irvine DJ. Enhancing humoral responses to a malaria antigen with nanoparticle vaccines that expand Tfh cells and promote germinal center induction. Proc Natl Acad Sci U S A. 2012;109(4):1080-1085.

8. De M, Ghosh PS, Rotello VM. Applications of nanoparticles in biology. Adv Mater Deerfield. 2008;20(22):4225-4241.

9. Wang L, Hess A, Chang TZ, et al. Nanoclusters self-assembled from conformation-stabilized influenza M2e as broadly cross-protective influenza vaccines. Nanomedicine. 2014;10(2):473-482.

10. Jiang W, KimBetty YS, Rutka JT, ChanWarren CW. Nanoparticlemediated cellular response is size-dependent. Nat Nanotechnol. 2008; 3(3): 145-150.

11. Rana S, Bajaj A, Mout R, Rotello VM. Monolayer coated gold nanoparticles for delivery applications. Adv Drug Deliv Rev. 2012;64(2): 200-216.

12. Wang B-Z, Xu R, Quan F-S, Kang S-M, Wang L, Compans RW. Intranasal immunization with influenza VLPs incorporating membraneanchored flagellin induces strong heterosubtypic protection. PLoS One. 2010;5(11):e13972.

13. Lu Y, Swartz JR. Functional properties of flagellin as a stimulator of innate immunity. Sci Rep. 2016;6:18379.

14. Weldon WC, Wang B-Z, Martin MP, Koutsonanos DG, Skountzou I, Compans RW. Enhanced immunogenicity of stabilized trimeric soluble influenza hemagglutinin. PLoS One. 2010;5(9):e12466.

15. Skountzou I, Martin Mdel P, Wang B, et al. Salmonella flagellins are potent adjuvants for intranasally administered whole inactivated influenza vaccine. Vaccine. 2010;28(24):4103-4112.

16. Kim Y-H, Jeon J, Hong SH, et al. Tumor targeting and imaging using cyclic RGD-PEGylated gold nanoparticle probes with directly conjugated iodine-125. Small. 2011;7(14):2052-2060.

17. Zhang M-X, Huang B-H, Sun X-Y, Pang D-W. Clickable gold nanoparticles as the building block of nanobioprobes. Langmuir. 2010;26(12): 10171-10176.

18. Zor T, Selinger Z. Linearization of the Bradford protein assay increases its sensitivity: theoretical and experimental studies. Anal Biochem. 1996; 236(2):302-308.

19. Lai C-H, Tang N, Jan J-T, et al. Use of recombinant flagellin in oilin-water emulsions enhances hemagglutinin-specific mucosal IgA production and IL-17 secreting T cells against $\mathrm{H} 5 \mathrm{~N} 1$ avian influenza virus infection. Vaccine. 2015;33(35):4321-4329.

20. WHO. Manual on Animal Influenza Diagnosis and Surveillance. 2002. Available from: http://www.wpro.who.int/emerging_diseases/ documents/manual_on_animal_ai_diagnosis_and_surveillance/en/. Accessed June 10, 2017. 
21. Ranjbar S, Haridas V, Jasenosky LD, Falvo JV, Goldfeld AE. A role for IFITM proteins in restriction of Mycobacterium tuberculosis infection. Cell Rep. 2015;13(5):874-883.

22. Wang Y-T, Lu X-M, Zhu F, et al. The use of a gold nanoparticlebased adjuvant to improve the therapeutic efficacy of $\mathrm{hNgR}-\mathrm{Fc}$ protein immunization in spinal cord-injured rats. Biomaterials. 2011;32(31): 7988-7998.

23. Niikura K, Matsunaga T, Suzuki T, et al. Gold nanoparticles as a vaccine platform: influence of size and shape on immunological responses in vitro and in vivo. ACS Nano. 2013;7(5):3926-3938.

24. Sokolova V, Westendorf AM, Buer J, Uberla K, Epple M. The potential of nanoparticles for the immunization against viral infections. J Mater Chem B. 2015;3(24):4767-4779.

25. Zhang S, Gao H, Bao G. Physical principles of nanoparticle cellular endocytosis. ACS Nano. 2015;9(9):8655-8671.

26. Oh N, Park J-H. Endocytosis and exocytosis of nanoparticles in mammalian cells. Int J Nanomedicine. 2014;9(suppl 1):51-63.

27. Ghiringhelli F, Apetoh L, Tesniere A, et al. Activation of the NLRP3 inflammasome in dendritic cells induces IL-1[beta]-dependent adaptive immunity against tumors. Nat Med. 2009;15(10):1170-1178.

28. Guermonprez P, Saveanu L, Kleijmeer M, Davoust J, van Endert P, Amigorena S. ER-phagosome fusion defines an MHC class I crosspresentation compartment in dendritic cells. Nature. 2003;425(6956): $397-402$.

29. Finlay BB, McFadden G. Anti-immunology: evasion of the host immune system by bacterial and viral pathogens. Cell. 2006;124(4):767-782.

30. Lee Y-T, Ko E-J, Lee Y, et al. CD47 plays a role as a negative regulator in inducing protective immune responses to vaccination against influenza virus. J Virol. 2016;90(15):6746-6758.

31. Pushko P, Sun X, Tretyakova I, et al. Mono- and quadri-subtype viruslike particles (VLPs) containing H10 subtype elicit protective immunity to H10 influenza in a ferret challenge model. Vaccine. 2016;34(44): 5235-5242.

32. Liu F, Sun X, Fairman J, et al. A cationic liposome-DNA complexes adjuvant (JVRS-100) enhances the immunogenicity and cross-protective efficacy of pre-pandemic influenza A (H5N1) vaccine in ferrets. Virology. 2016;492:197-203.
33. Bernasconi V, Norling K, Bally M, Hook F, Lycke NY. Mucosal vaccine development based on liposome technology. J Immunol Res. 2016; 2016:5482087.

34. Tao W, Ziemer KS, Gill HS. Gold nanoparticle-M2e conjugate coformulated with $\mathrm{CpG}$ induces protective immunity against influenza A virus. Nanomedicine (Lond). 2014;9(2):237-251.

35. Sokolova V, Knuschke T, Kovtun A, Buer J, Epple M, Westendorf AM. The use of calcium phosphate nanoparticles encapsulating toll-like receptor ligands and the antigen hemagglutinin to induce dendritic cell maturation and T cell activation. Biomaterials. 2010;31(21): 5627-5633.

36. Guermonprez P, Valladeau J, Zitvogel L, Théry C, Amigorena S. Antigen presentation and T cell stimulation by dendritic cells. Annu Rev Immunol. 2002;20(1):621-667.

37. Gregory A, Williamson ED, Prior JL, et al. Conjugation of Y. Pestis F1-antigen to gold nanoparticles improves immunogenicity. Vaccine. 2012;30(48):6777-6782.

38. Pasare C, Medzhitov R. Control of B-cell responses by toll-like receptors. Nature. 2005;438(7066):364-368.

39. Kasturi SP, Skountzou I, Albrecht RA, et al. Programming the magnitude and persistence of antibody responses with innate immunity. Nature. 2011;470(7335):543-547.

40. de Titta A, Ballester M, Julier Z, et al. Nanoparticle conjugation of $\mathrm{CpG}$ enhances adjuvancy for cellular immunity and memory recall at low dose. Proc Natl Acad Sci U S A. 2013;110(49):19902-19907.

41. Lee C, Gaston MA, Weiss AA, Zhang P. Colorimetric viral detection based on sialic acid stabilized gold nanoparticles. Biosens Bioelectron. 2013;42:236-241.

42. Wei J, Zheng L, Lv X, et al. Analysis of influenza virus receptor specificity using Glycan-functionalized gold nanoparticles. ACS Nano. 2014;8(5):4600-4607.

43. Blander JM, Medzhitov R. Toll-dependent selection of microbial antigens for presentation by dendritic cells. Nature. 2006;440(7085):808-812.

44. Heit A, Schmitz F, Haas T, Busch DH, Wagner H. Antigen coencapsulated with adjuvants efficiently drive protective $\mathrm{T}$ cell immunity. Eur J Immunol. 2007;37(8):2063-2074. 


\section{Supplementary materials}
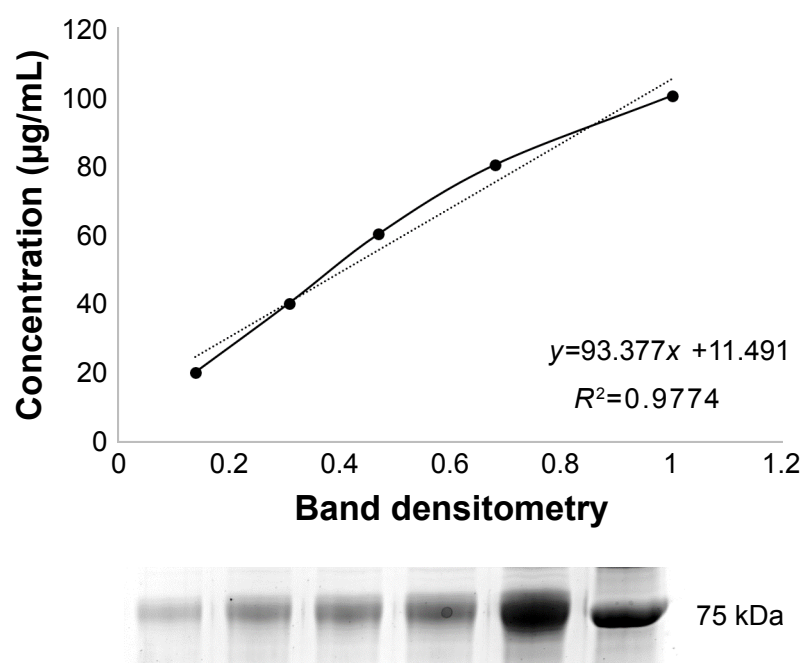

Figure SI Quantification of AuNP-conjugating HA protein using band densitometry method.

Abbreviations: AuNPs, gold nanoparticles; HA, hemagglutinin.

Table SI Immunization strategies

\begin{tabular}{llllll}
\hline Groups & Vaccine & Number of animals & Concentration of vaccine & Number of inoculation & Route \\
\hline $\mathrm{I}$ & Naïve & 5 & & & I \\
2 & Soluble HA/FliC & 5 & $5 \mu \mathrm{g} \mathrm{HA} ; 0.25 \mu \mathrm{g} \mathrm{FliC}$ & $\mathrm{I}$ & IN \\
3 & AuNPs-HA & 5 & $5 \mu \mathrm{g} \mathrm{HA}$ & $\mathrm{I}$ & IN \\
4 & AuNPs-HA/FliC & 5 & $5 \mu \mathrm{g} \mathrm{HA} ; 0.25 \mu \mathrm{g} \mathrm{FliC}$ & \\
\hline
\end{tabular}

Abbreviations: AuNPs, gold nanoparticles; FliC, flagellin; HA, hemagglutinin; IN, intranasal.

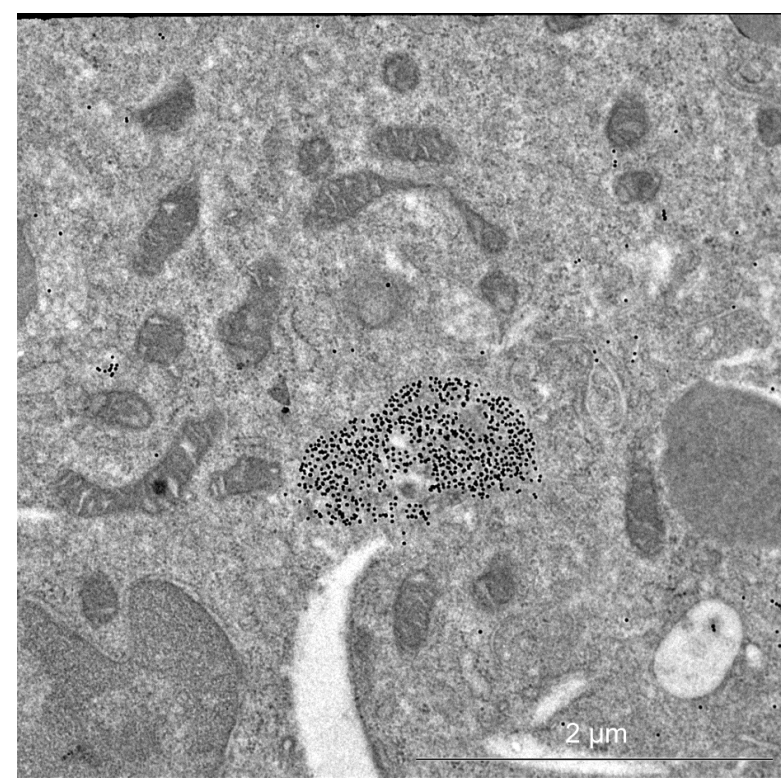

Figure S2 TEM image of BMDCs treated with AuNPs-HA/FliC for $18 \mathrm{~h}$.

Abbreviations: AuNPs, gold nanoparticles; BMDCs, bone marrow-derived dendritic cells; FliC, flagellin; HA, hemagglutinin; TEM, transmission electron microscope. 
Table S2 Protein conjugation efficiency and stability of different AuNP surface modification methods

\begin{tabular}{llllll}
\hline Treatments & Band density $(\mu \mathrm{g} / \mathbf{m L})$ & $\mathbf{0 . 5} \mathbf{~ M ~ H C l}$ & $\mathbf{0 . 5} \mathbf{~ M ~ N a O H}$ & $\mathbf{~ M ~ N a C l}$ & FBS \\
\hline FliC control & 400 & & & & \\
Physical absorption & $24 \pm 2$ & $5 \mathrm{~h}$ & $10 \mathrm{~h}$ & Stable & Partial aggregation \\
Carbodiimide chemistry & $5.3 \pm 2.7$ & $5 \mathrm{~h}$ & $10 \mathrm{~h}$ & Stable & Partial aggregation \\
Click chemistry & $50.5 \pm 0.5$ & Stable & Stable & Stable & Stable \\
Metal chelating & $50 \pm 4$ & $5 \mathrm{~h}$ & Stable & Stable & Stable \\
\hline
\end{tabular}

Notes: Metal: metal chelating through NTA linker. Click: click chemistry reaction via azide-alkyne reaction. Absorption: direct physical absorption between AuNPs and target proteins. Carbodiimide: AuNPs were modified with $\mathrm{SH}-\mathrm{CH}_{2}-\mathrm{CH}_{2}-\mathrm{NH}_{2}$ then coupled with FliC using EDC/NHS cross-linkers.

Abbreviations: AuNPs, gold nanoparticles; EDC, $\mathrm{N}$-(3-dimethylaminopropyl)-N'-ethylcarbodiimide hydrochloride; FBS, fetal bovine serum; FliC, flagellin; NHS, $N$-hydroxysuccinimide.

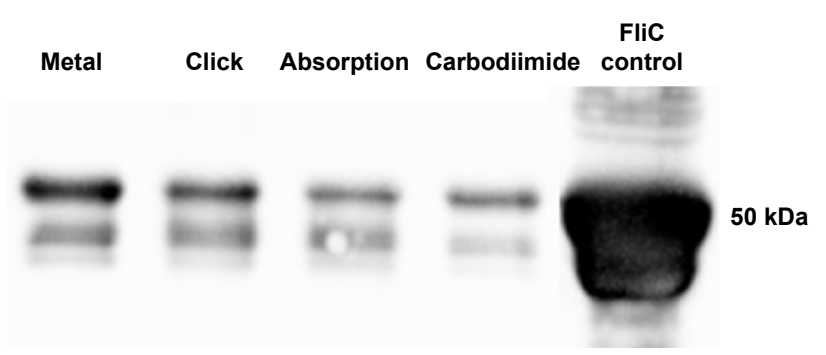

Figure S3 Western blotting analysis of AuNPs with different surface modification methods.

Abbreviation: FliC, flagellin.

\section{Publish your work in this journal}

The International Journal of Nanomedicine is an international, peerreviewed journal focusing on the application of nanotechnology in diagnostics, therapeutics, and drug delivery systems throughout the biomedical field. This journal is indexed on PubMed Central, MedLine, CAS, SciSearch $®$, Current Contents ${ }^{\circledR} /$ Clinical Medicine,
Journal Citation Reports/Science Edition, EMBase, Scopus and the Elsevier Bibliographic databases. The manuscript management system is completely online and includes a very quick and fair peer-review system, which is all easy to use. Visit http://www.dovepress.com/ testimonials.php to read real quotes from published authors. 